\title{
Clinical and pathological findings in a case of hepatolenticular degeneration treated with penicillamine
}

\author{
SERGE DUCKETT ${ }^{1}$, N. E. FRANCE, AND P. G. WALLIS \\ From the Fountain Hospital and the Queen Elizabeth Hospital for Children, Hackney, London
}

Hepatolenticular degeneration, a condition inherited in an autosomal recessive fashion, is generally thought to be due to a biochemical defect associated with the retention of copper in the tissues, principally the brain, liver, and kidneys, an increased excretion of the metal in the urine, and a low level of caeruloplasmin, the copper-binding alpha-globulin in the plasma. A number of products have been used to increase the copper excretion of patients suffering from this disease. It was Cumings in 1948 who originally suggested that such a product, dimercaprol (B.A.L.), would be of use, and shortly afterwards Denny-Brown and Porter (1951) employed it with some success.

Penicillamine was introduced for the treatment of hepatolenticular degeneration by Walshe (1956). Since then, various clinical observers have reported it to be of considerable aid as a 'decoppering' and therapeutic agent. Penicillamine is obtained by the controlled decomposition of penicillin. It is an orally administered chelating agent capable by complexing in situ of increasing the body's elimination of certain toxic metal ions, such as copper, mercury, and lead.

The following case is the first treated with penicillamine to be examined after death. It was previously referred to by Walshe (1960) as Case No. 2.

\section{CASE REPORT}

E.M., a girl born on 2 May 1946, showed the first signs of hepatolenticular degeneration in July 1955. She was an illegitimate child with no known history of this disease on her mother's side. No information is available about the father or his family. She was a healthy and intelligent child until the age of 9 when she was noticed to walk unsteadily, her movements being stiff and awkward. She developed a fine tremor of the hands and her speech became slurred. She became emotionally unstable and her intelligence declined so that she was gradually put back several classes at school.

At the age of 11, she was admitted to hospital and found to be a physically well-developed girl with an

'Present address: Maida Vale Hospital for Nervous Diseases, London. expressionless face. She had an intention tremor of the arms and some loss of coordination in leg movements with increased muscular tone and brisk reflexes of all limbs. There were bilateral Kayser-Fleischer rings with normal fundi, considerable enlargement of the spleen, and a slightly enlarged liver.

The serum bilirubin $(2.0 \mathrm{mg} . / 100 \mathrm{ml}$.) level and zinc sulphate turbidity ( 6 units) were slightly raised. The urinary copper excretion was increased to about $500 \mu \mathrm{g}$. per 24 hours, the upper normal being $80 \mu \mathrm{g}$. per 24 hours. No serum copper oxidase activity was detected using p-phenylenediamine as substrate, the normal range being 150 to 225 units. Gross amino-aciduria was demonstrated by paper chromatography and the caeruloplasmin level of the blood was one eighth of the normal. The diagnosis of hepatolenticular degeneration was thus confirmed.

A 10-day course of intramuscular B.A.L., $50 \mathrm{mg}$. twice daily, was given, but this had no effect on the clinical symptoms, nor did it increase the urinary copper excretion. A course of penicillamine, $1 \mathrm{~g}$. daily, was begun on 9 April 1957, and urinary copper excretion was estimated weekly (Table I). The treatment ended 10 weeks later, owing to shortage of supply.

TABLE I

24-HOURLY COPPER URINARY EXCRETION OF COPPER TAKEN AT WEEKLY INTERVALS

\begin{tabular}{lrcc} 
& Date & $\begin{array}{l}\text { 24-Hour } \\
\text { Volume }(\mathrm{ml} .)\end{array}$ & $\begin{array}{l}\text { 24-Hour } \\
\text { Copper }(\mu \mathrm{g} .)\end{array}$ \\
\hline Before penicillamine & 9.4 .57 & 820 & 820 \\
After penicillamine & 17.4 .57 & 465 & 1,220 \\
After penicillamine & 24.4 .57 & 1,925 & 1,630 \\
After penicillamine & 26.4 .57 & 1,255 & 1,580 \\
After penicillamine & 27.4 .57 & 1,540 & 1,680 \\
After penicillamine & 8.5 .57 & 445 & 920 \\
After penicallimine & 15.557 & 545 & 800 \\
After penicillamine & 22.5 .57 & 665 & 850 \\
After penicillamine & 29.5 .57 & 1,415 & 800 \\
After penicillamine & 5.6 .57 & 890 & 1,140 \\
After penicillamine & 12.6 .57 & 1,245 & 960 \\
After penicillamine & 19.6 .57 & 1,200 & 890
\end{tabular}

Her emotional lability became worse during the treatment and she had some violent episodes. The copper excretion was increased. She was discharged on 29 June 1957. Two-and-a-half months later it was felt that her 
condition had not changed since she had left the hospital. She was re-admitted for a few days on 14 October 1957 for re-assessment. Clinical examination showed no change in the nervous system except that the fine tremor of both arms seemed more accentuated on the right side. The spleen was larger, filling the left hypochondrium, and there were some petechiae on the right side of the chest. There was a slightly increased zinc turbidity test $\left(5 \frac{1}{2}\right.$ units); the prothrombin time was increased to 32 seconds (normal $=17$ seconds); the caeruloplasmin level was still low (one twelth of normal); the 24-hour urinary excretion of copper was decreased to 136-152 $\mu \mathrm{g}$. when compared with the original pre-penicillamine figure of $500 \mu \mathrm{g}$. She was discharged on 17 October 1957. A second course of oral penicillamine, $150 \mathrm{mg}$. daily, was begun on 11 December 1957; this treatment continued until 24 June 1958 when she was admitted to hospital, her condition having suddenly worsened after a poliomyelitis vaccine injection. She had developed marked tremor of all limbs and she was continually opening and closing her mouth and grimacing. Her speech was very slurred, her neck was stiff, and she was unable to walk.

On admission to hospital she was fully conscious and cooperative. The left plantar response was extensor. Muscular coordination was poor; there was marked dysdiadokokinesia; eye movements were limited and the pupils were dilated and reacting to light. There were ulcers on the palate and petechiae on the right arm. One week after admission her temperature suddenly rose to $104^{\circ} \mathrm{F}$., the throat was inflamed, there were rales in the chest, and small cervical glands were palpable in the neck. She gradually became worse and sank into coma. The diagnosis of hepatic coma was made. She passed blood per rectum and died on 12 July 1958 with terminal haematemesis.

\section{POST-MORTEM FINDINGS}

CENTRAL NERVOUS SYSTEM The brain weighed $1,307 \mathrm{~g}$. There was a suggestion of widening of sulci in the frontal region. On sectioning the brain coronally, slight ventricular dilatation was seen with faint ependymal roughening at the level of the caudate nucleus. The striate body appeared to be slightly red. The nucleus subthalamicus appeared to be normal. In the left putamen there was a dilated space suggestive of perivascular rarefaction. The substantia nigra was paler than normal.

LIVER This organ weighed $848 \mathrm{~g}$. and showed the typical appearance of portal cirrhosis with nodules

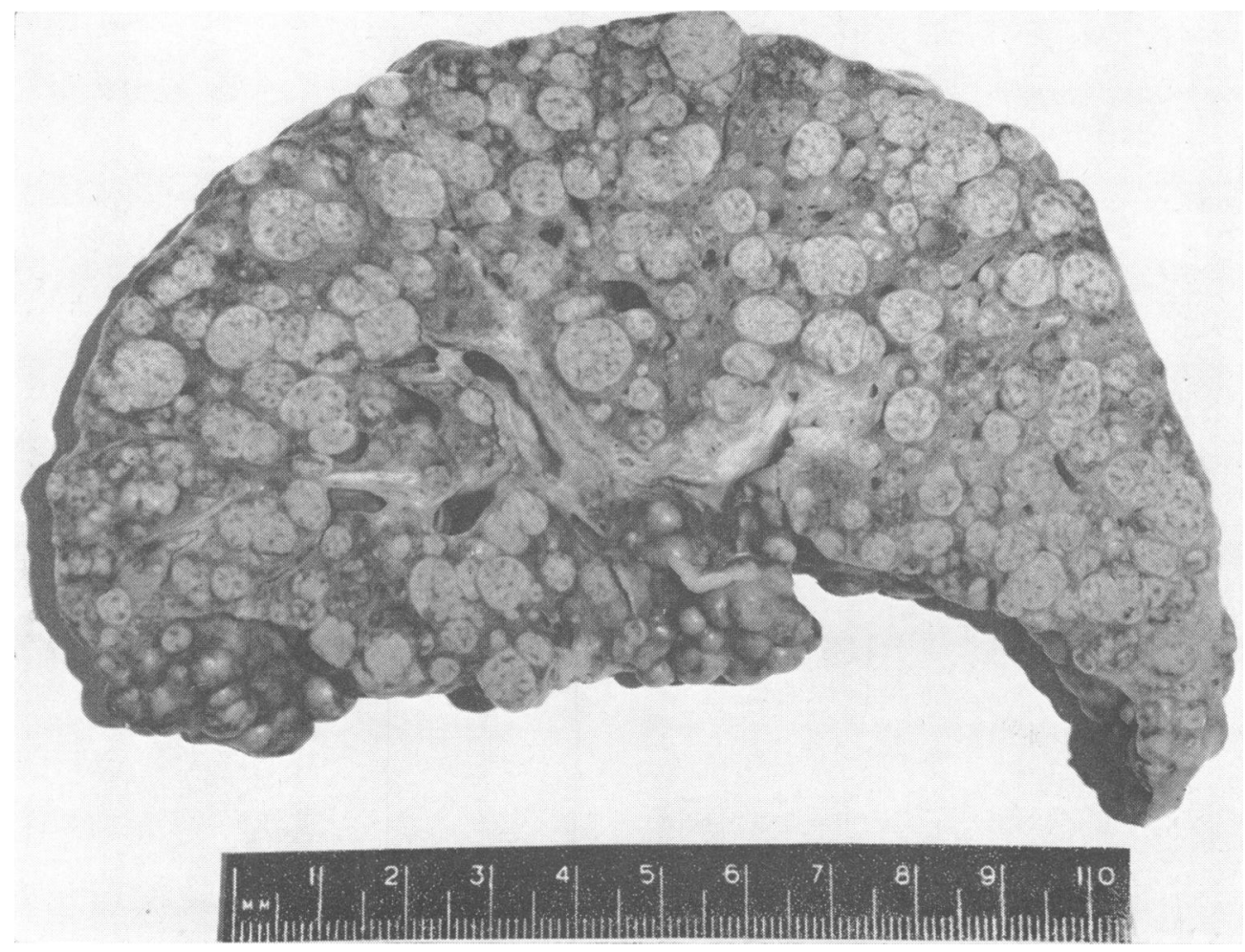

FIG. 1. Cut surface of the liver showing typical cirrhosis. 
varying from a few millimetres to $1.5 \mathrm{~cm}$. in diameter (Fig. 1), separated by bands of grey fibrous tissue. The gall bladder contained normal bile and enlarged lymph nodes in the porta hepatica were stained green.

SPLEEN The organ was greatly enlarged (569 g.) and congested.

OTHER ORGANS The portal vein appeared normal and there were no demonstrable varices of the oesophagus, rectum, or umbilicus. There was moderately severe ascites and bilateral hydrothorax. Numerous pinpoint erosions were present in the stomach which, together with the small intestine, contained considerable amounts of altered blood. The eyes were not examined.

\section{HISTOLOGY REPORT}

Representative blocks of the frontal, parietal, temporal and occipital lobes, the hippocampus, the basal ganglia, the cerebellum, and the brain-stem were embedded in celloidin and paraffin. Serial sections were prepared of the basal ganglia. The usual general and neurological stains were used, and frozen material was also employed for fat-staining and silver impregnation methods.

The chief change was rarefaction of tissue affecting the grey matter of the striate body (Fig. 2), more marked around a few of the blood vessels where the perivascular spaces were considerably dilated. Some of the 'empty spaces' tended to coalesce, but this never amounted to a complete breakdown of substantial areas. The white matter in the striate body was relatively intact, showing only some uneven staining and irregularity in outline of the fibres. There was little reactive fibrous gliosis except for one small perivascular area in the putamen. Most of the astrocytes in the affected area showed clasmatodendrosis. Alzheimer type II cells, with large vesicular round or oval nuclei and little or no cytoplasm, were quite numerous and there were a few Alzheimer type I cells. A few Opalski cells, with small, eccentric, darkly staining nuclei and granular cytoplasm staining an orange-brown with the Van Gieson stain were seen in the putamen, the globus pallidus, the caudate nucleus, the thalamus, particularly the medial nuclei, the subthalamic nuclei, and in the brain-stem. Throughout the affected area there was a moderate number of diffusely distributed fat-laden compound granular corpuscles. The blood vessels did not appear to be increased in number.

The large nerve cells of the striate body were scarcer than normal and most of the remaining

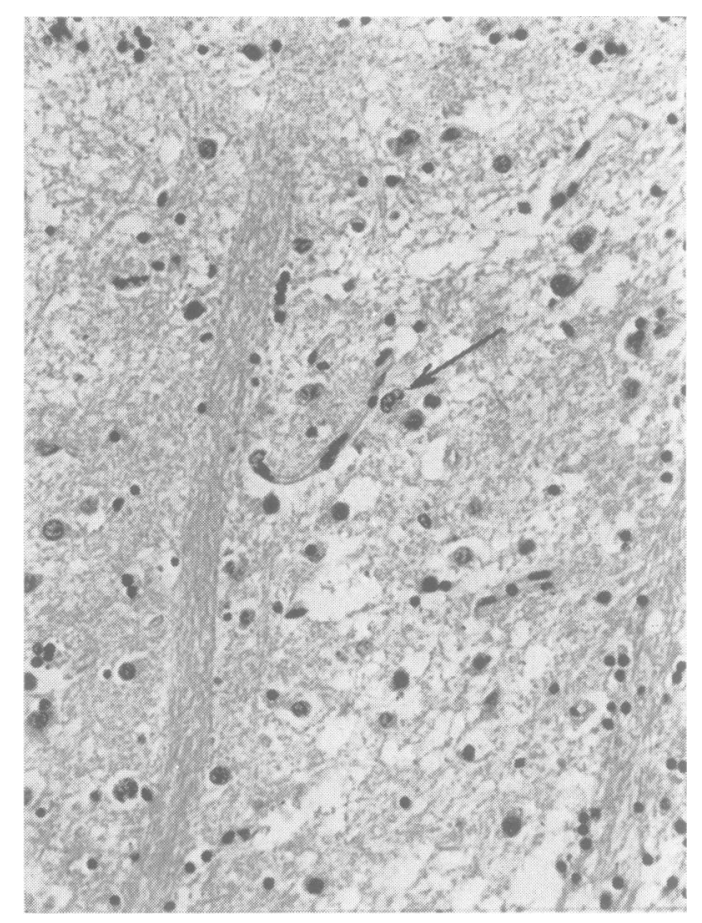

FIG. 2. Rarefaction with some loss of nerve cells in the grey matter of the putamen. An Alzheimer cell is seen arrowed. Haematoxylin and eosin $\times 220$.

ones showed central chromatolysis and pyknosis. The number of small nerve cells was seemingly normal. The axis cylinders stained normally and seemed to be well preserved.

The only pathological change in the cerebral cortex was the presence of many Alzheimer II cells. The globus pallidus seemed normal. There were Alzheimer II cells in the thalamus and subthalamic nuclei. The cerebellum showed focal loss of Purkinje cells, with satellitosis and a good deal of proliferation of Bergmann cells and glia. There were Alzheimer type I and type II cells in the mid-brain, particularly in the substantia nigra, and less in the red nucleus, with widespread rarefaction of tissue in the mid-brain. No demyelination or gliosis was seen here.

The spinal cord was not available for examination.

The liver showed typical portal cirrhosis with groups of lobules surrounded by wide zones of connective tissue infiltrated by lymphocytes and showing numerous small bile ducts. Bile pigment was present in many parenchyma cells and canaliculi and one area showed almost complete necrosis. The spleen showed the histological features of chronic venous congestion. 


\section{BIOCHEMICAL FINDINGS}

The chemical analysis of the brain, liver, and spleen was carried out by Professor J. N. Cumings (Table II). All the areas of the brain contained six to 10 times the normal amount of copper whereas the liver only contained double the normal content. This finding serves to confirm Professor Cumings' view that penicillamine is more effective in reducing the copper content of the liver than it is that of the brain.

TABLE II

COPPER CONTENT OF BRAIN, LIVER, AND SPLEEN

Copper ( $\mu \mathrm{g} . / 100 \mathrm{mg} . \quad$ Water $(\%)$ of dry tissue)

\begin{tabular}{lll}
\hline Frontal grey & $20 \cdot 0$ & $87 \cdot 4$ \\
Frontal white & $25 \cdot 6$ & $72 \cdot 2$ \\
Occipital grey & $25 \cdot 0$ & $85 \cdot 1$ \\
Occipital white & $27 \cdot 2$ & $71 \cdot 6$ \\
Parietal grey & $20 \cdot 8$ & $84 \cdot 2$ \\
Parietal white & $24 \cdot 4$ & $72 \cdot 3$ \\
Corpus striatum & $22 \cdot 8$ & $83 \cdot 4$ \\
Thalamus & $27 \cdot 8$ & $78 \cdot 1$ \\
Spleen & $16 \cdot 8$ & $82 \cdot 8$ \\
Liver & $22 \cdot 2$ & $\mathbf{8 3} \cdot 6$
\end{tabular}

COMMENT

The neuropathological changes in hepatolenticular degeneration vary considerably in extent and severity. At one end of the scale there are cases with no macroscopically recognizable lesions of the central nervous system (this type was described by Alzheimer as the so-called pseudo-sclerosis of Westphal-Strumpell) and at the other end there is gross breakdown of tissue, with cyst formation seen in the juvenile type of hepatolenticular degeneration or Wilson's disease.
The present case falls into the category showing only mild neural changes. There is no neuropathological evidence that the treatment had influenced the pathogenesis of the disease, but this possibility cannot be entirely excluded. The clinical and histological evidence in this case suggests, however, that the action of penicillamine has not affected the course of the disease, whatever its effect on copper excretion.

\section{SUMMARY}

The clinical, histological, and biochemical findings in a case of hepatolenticular degeneration treated with penicillamine are presented. This treatment had no appreciable effect on the clinical course which could be due to the low dosage, although the urinary excretion of copper was increased. The histological picture is that to be expected in this disease. The copper analysis of the brain and liver suggests that penicillamine is more effective in reducing the copper content of the liver than that of the brain.

We wish to thank Dr. C. T. Potter for the clinical details, Dr. B. Levin for the biochemical results, Dr. L. Crome and Dr. J. Stern for advice and encouragement in the preparation of this paper, and Professor J. N. Cumings for his advice and estimations of copper in various organs.

\section{REFERENCES}

Cumings, J. N. (1948). Brain, 71, 410.

Denny-Brown, D., and Porter, H. (1951). New Engl. J. Med., 245, 917.

Walshe, J. M. (1956). Lancet, 1, 25.

- (1960). Ibid., 1, 188. 